\title{
Advancements in the knowledge of induced tooth movement: Idiopathic osteosclerosis, cortical bone and orthodontic movement
}

\author{
Alberto Consolaro', Renata Bianco Consolaro²
}

Moving teeth orthodontically through the dense trabecular bone and cortical areas may require a reduction in the intensity and/or concentration of the applied forces. In part, the orthodontic applied forces are dissipated and reduced by bone deflection, which normally occurs by a slight degree of elasticity of bone tissue in normal conditions. In areas of dense trabecular and in cortical bone this deflection should be insignificant or nonexistent. If there is no reduction in the intensity of the forces in these mentioned regions, the entire force will focus on the structure of the periodontal ligament, increasing the risk of death of cementoblasts, hyalinization and root resorption. Further studies could assess the prevalence of these consequences in populations selected for this purpose, so that would no longer be randomly observed notes.

Keywords: Cortical bone. Idiopathic osteosclerosis. Chronic focal sclerosing osteitis [osteomyelitis]. Orthodontic movement. Induced tooth movement.

The orthodontic movement depends on the application of forces to the tooth promoting compression of the periodontal ligament. The deformation of cells and their cytoskeletons, in addition to the reducing blood flow and hypoxia, lead to cell stress with increased release of mediators that stimulate bone resorption in the surface of the periodontal alveolar bone. Thus, teeth move orthodontically.

In training for the application of orthodontic forces, it is common to have uniformity in the procedures. However, the bone has a great variability in the trabecular bone density, as well as in its cortical thickness and morphology of the bone crest.

This extreme variability, when extreme, may influence significantly in more or less symptoms during orthodontic movement as well as the risk of root resorption.

\section{TRABECULAR BONE DENSITY}

The density of trabecular bone varies according with the skeletal region. In the maxilla, the variability of the trabecular bone density is large, even when considering different areas of a same maxilla or mandible.
${ }^{1}$ Full Professor, FOB, and Post-Graduation course, FORP - São Paulo University.

${ }^{2} \mathrm{PhD}$ Professor, FOA, Unesp and Integrated Adamantinenses School.

» The authors report no commercial, proprietary, or financial interest in the products or companies described in this article.
How to cite this article: Consolaro A, Consolaro RB. Advancements in the knowledge of induced tooth movement: Idiopathic osteosclerosis, cortical bone and orthodontic movement. Dental Press J Orthod. 2012 July-Aug;17(4):12-6.

Submitted: March 26, 2012 - Revised and accepted: march 31, 2012

Contact address: Alberto Consolaro

E-mail: consolaro@uol.com.br 


\title{
Avanços no conhecimento da movimentação dentária induzida Osteoesclerose idiopática, corticais ósseas e 0 movimento ortodôntico
}

\author{
Alberto Consolaro', Renata Bianco Consolaro²
}

Movimentar ortodonticamente os dentes por áreas densas do trabeculado ósseo e pelas corticais pode requerer uma redução na intensidade e/ou na concentração das forças aplicadas. Em parte, as forças ortodônticas aplicadas são dissipadas e reduzidas pela deflexão óssea que ocorre pelo discreto grau de elasticidade do tecido ósseo em condições de normalidade. Nas áreas de trabeculado denso e nas corticais, essa deflexão deve ser irrisória ou inexistente. Se não houver uma redução na intensidade das forças nessas regiões citadas, toda a força incidirá sobre a estrutura do ligamento periodontal, aumentando o risco de morte dos cementoblastos, hialinização e reabsorções radiculares. Novos trabalhos poderiam avaliar a prevalência dessas consequências em casuísticas selecionadas para essa finalidade, que, assim, deixariam de ser observações aleatórias.

Palavras-chave: Cortical óssea. Osteoesclerose idiopática. Osteíte crônica esclerosante focal. Movimentação ortodôntica. Movimentação dentária induzida.

${ }^{1}$ Professor Titular da FOB e da Pós-graduação da FORP - Universidade de São Paulo.

${ }^{2}$ Professora Doutora Substituta de Patologia da FOA-Unesp e das Faculdades Adamantinenses Integradas.
Como citar este artigo: Consolaro A, Consolaro RB. Advancements in the knowledge of induced tooth movement: Idiopathic osteosclerosis, cortical bone and orthodontic movement. Dental Press J Orthod. 2012 July-Aug;17(4):12-6.

Enviado em: 26 de março de 2012 - Revisado e aceito: 31 de março de 2012

Endereço para correspondência: Alberto Consolaro

E-mail: consolaro@uol.com.br 
This variability is related to structural adaptation to functional demands. The more physical or biologically required, within the normal range, the denser the trabecular bone will be, the marrow spaces will become smaller and in greater number in the radio and tomographic ${ }^{1}$ images (Figs 1 and 2). The bone cells work in the remodeling to adequate the tissue to functional demands by increasing or decreasing their structures. Thus, the trabeculae may be bigger or smaller, narrower or wider; thus, the cortical may increase or decrease its thickness according to the functional demands required (Figs 1 and 2).

In images, the denser the trabecular bone, we tend to say that the same is suffering sclerosis. The term bone sclerosis is usually reserved for the densest areas of trabecular bone, where it is assumed that passed the normal morphologic limits. ${ }^{2}$ In some texts sclerosis is used in place of the term bone condensation.

An area can typically presents with bone as dense as the anterior region of the mandible, without which we must call it as it represents a bone sclerosis of trabecular variability given a functional demand. When a certain situation or illness increases bone density usually adds the terms sclerosing or condensing to its name, especially for being a pathological nature.

When the trabecular bone present is less dense, it tends to assert that it is getting loose, spongy or yet refers to these as areas of bone rarefaction, by analogy to thin air. In regions of the mandibular angle or later the upper and lower third molars, including the tuberosity of the maxilla, there are patients with very loose areas or with normal bone rarefactions.

\section{Focal Sclerosing Osteitis versus Idiopathic Osteosclerosis}

The inflammatory osteitis is located, restricted to focal areas and less aggressive, which may involve the various components of bone. ${ }^{2}$ Almost always related to aggressive agents of low intensity and long duration, such as endodontic and periodontal lesions (Figs 1 and 2). In chronic periapical lesions a localized inflammation and thin bone in the periapex is commonly established, and finally an osteitis in these cases are given specific names such as periapical granuloma, chronic dentoalveolar abscess and other well-known names. These areas serve for the thin bone to give way to exudade fluid and cells and inflammatory infiltrate, respectively.

In bone rarefaction, the causes act directly on the site, but the adjacent bone receives even smaller stimuli that accumulate the same inflammatory mediators, but in lower concentrations which reverse the stimulation of resorption to bone
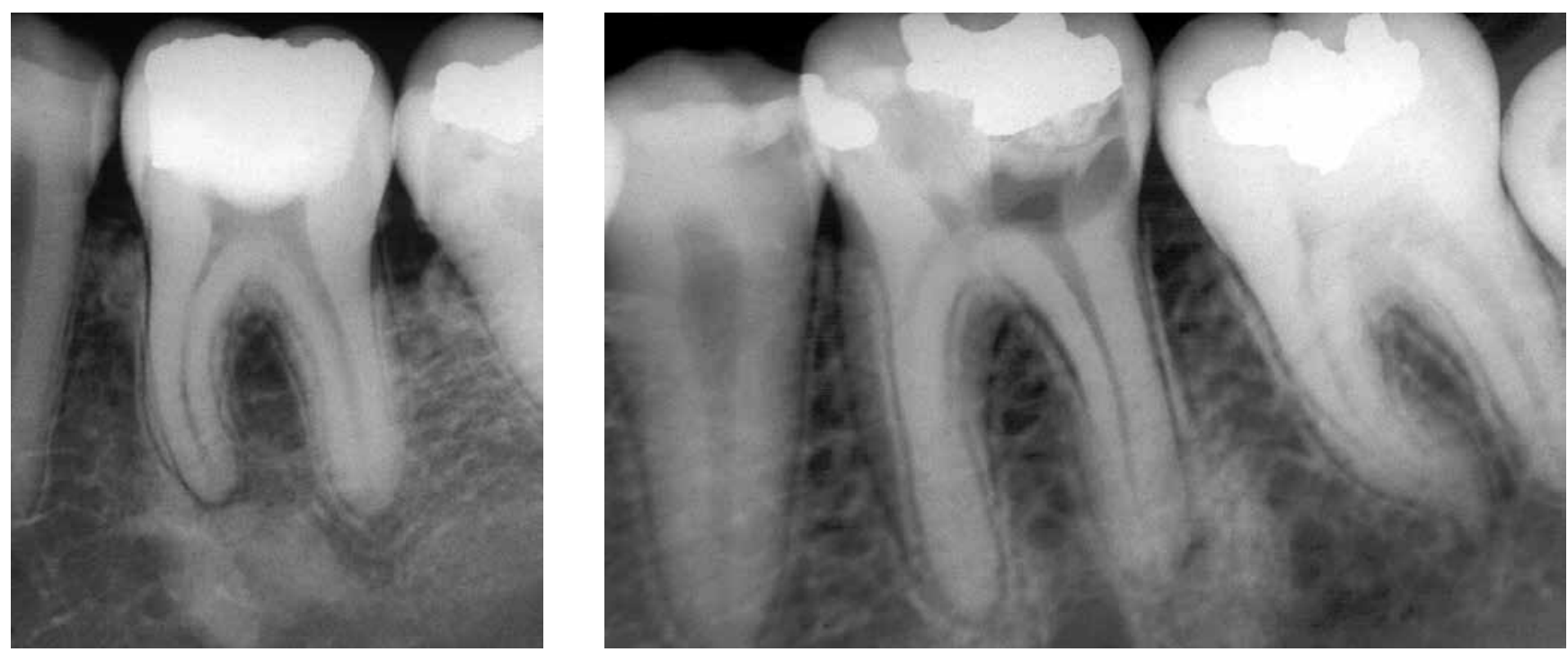

Figure 1 - Focal chronic sclerosing osteitis related to pulp necrosis and chronic periapical lesion, with small and irregular thin bone areas around the root canal opening, with predominant radiopaque images in the surroundings of thin bone areas. 


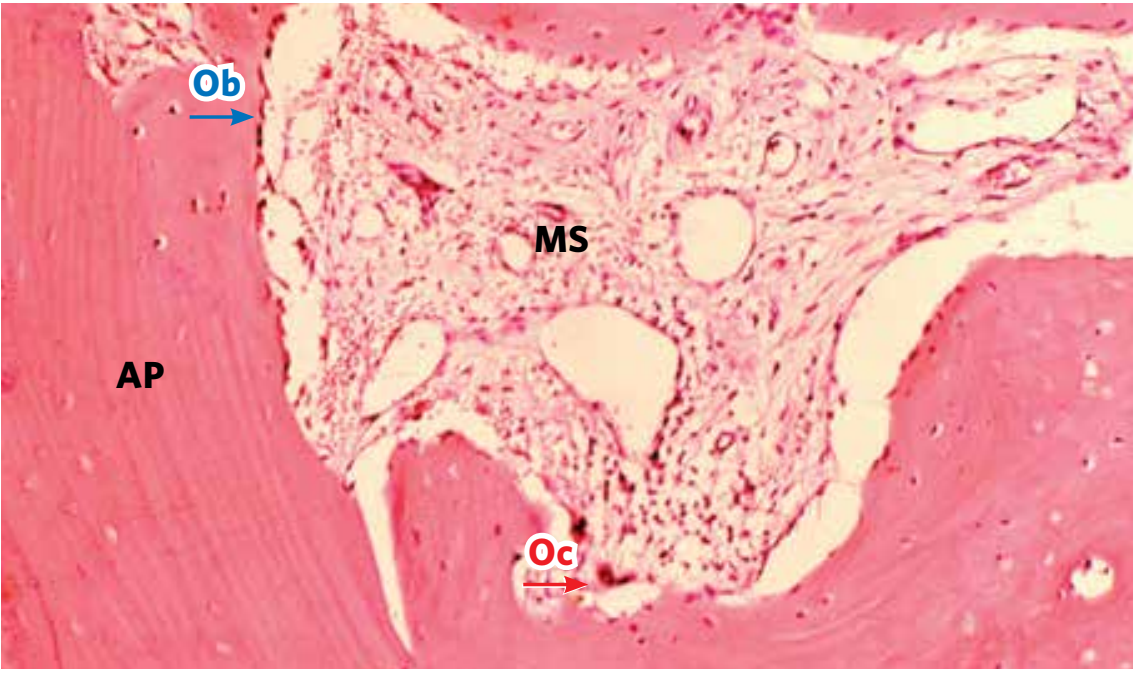

Figure 2 - Focal chronic sclerosing osteitis, demonstrating reduction of the medullary space (MS) filled in by conjunctive tissue with a discreet and difuse mononuclear infiltrate. The trabeculae are thick, with well defined layers of apposition (AP). Ob=osteoblasts; Oc=osteoclastas. (HE, 25x).

even though approximately $30 \%$ of the cases no longer return to normal. In other words, with root canal therapy, dental extraction, periodontal treatment or any other therapeutic approach, a focal sclerotic bone area may indefinitely remain in that place. ${ }^{2}$ After a few months or years, with remodeling and morphological upgrading of the site, without a prior well documented history (Fig 3), it will be very difficult to understand or identify any cause that induced that "abandoned" focal sclerotic bone area.

The term "Idiopathic Osteosclerosis" - also known as Dense Bone

formation (Figs 1 and 2). The adjacent bone thereby increase its density and suffers sclerosis. The osteitis, as a whole, starts to present several sclerotic areas around the rarefact area. ${ }^{2}$ In most affected cases radiopaque or neighboring dense areas predominate in the overall image of the process. In these cases the lesion is now diagnosed as Chronic Focal Sclerosing Osteitis. In some texts and reports it can be named as Chronic Focal Condensing Osteitis. The term "focal" can often be replaced by the term "local".

If the cause of Chronic Focal Sclerosing Osteitis is removed the inflammation process disappears, and, in general, the region remains indefinitely with a bone sclerosis which will be reshaped with time,
Isle or simply Focal Idiopathic Bone Sclerosis - is the most commonly used to identify focal sclerotic areas without identifying the cause-effect relationship (Fig 3). They are irregular and located radiopaque areas which continue naturally with the surrounding trabeculae without any line or radiolucent halo in outline or limit. The presence of a radiolucent halo indicates a fibrous capsule, which is typical of neoplastic diseases such as Fibrodysplasia Ossificans, osteomas, and odontomas, for example.

The Idiopathic Osteosclerosis without an identifiable cause, may have been earlier a Chronic Focal Sclerosing Osteitis with defined cause which was eliminated, but without documentation of their previous history it is impossible to make definitive
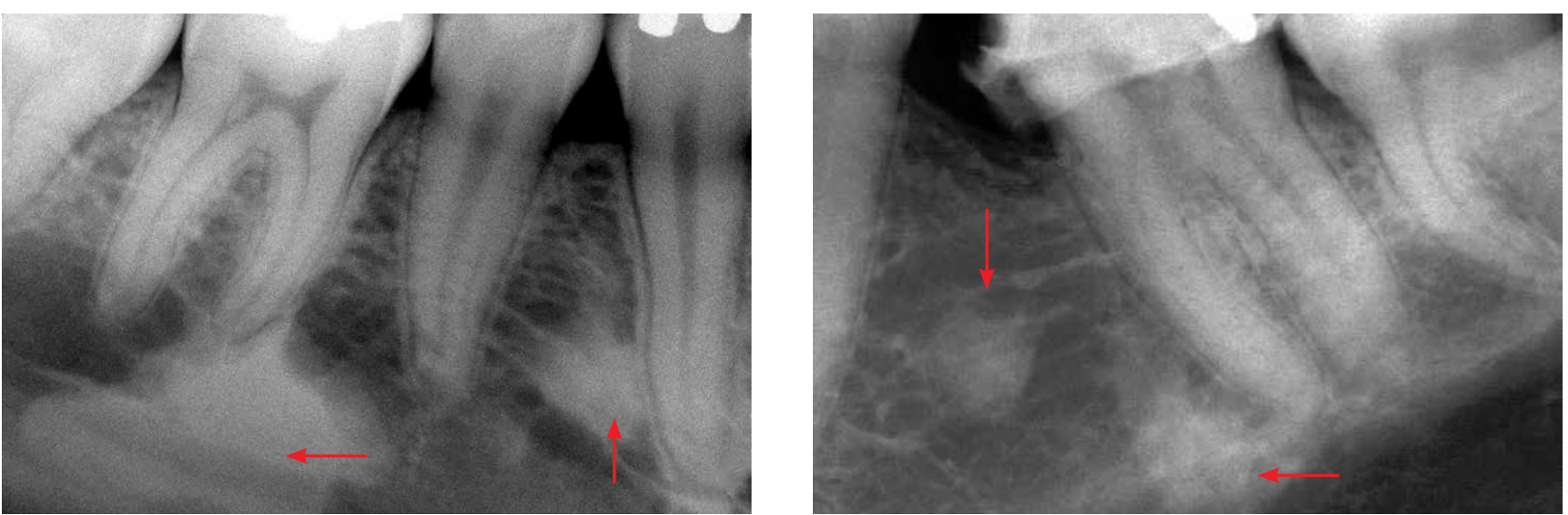

Figure 3 - Idiopathic Osteosclerosis (arrows) without cause-effect identification. In the past, some low intensity and long duration trauma may have happened in the area. The sclerotic areas persisted indefinitely and, very slowly, can disappear with constant and normal bone remodeling. 
statements. In many cases, the cause may be related to primary teeth with inter-radicular lesions, occlusal trauma, chronic periapical diseases, repair of bone surgery procedures that were used as autogenous bone grafting and other procedures.

The bone in an Idiopathic Osteosclerosis has structure and normal function, the difference is in the higher trabecular density. In this region teeth can be moved, osseointegrating implants and mini implants can be applied without further consequences, as long as in the region there is no infectious microbial component.

\section{SPECIFIC CARE FOR TOOTH MOVEMENT INTO SCLEROTIC AREAS}

In idiopathic osteosclerosis, the cells and other bone structures are normal. Remodeling is done normally, but takes longer, because as the trabeculae are thicker and the medullary spaces are very small, there are fewer surfaces exposed to the activity of the clasts. The more cancellous is the bone; more available surfaces are suitable for the action of the cells in bone remodeling units, especially the clasts, by allowing a faster process. In areas of Idiopathic Osteosclerosis, remodeling or turnover happens in a slower pace, as occurs in the cortex when compared with the trabecular bone.

The forces in orthodontic movement induce a bone deflection, a structural deformation that absorbs a small part of the applied force, reducing the effects on the periodontal ligament. Specifically, in the periodontal ligament, most of the applied forces are imposed on the vessels and cells, with stress, releasing and increasing the concentration of mediators required for the alveolar bone resorption for tooth movement to occur.

The integrity of the periodontal ligament and their cells is very important for tooth movement to occur. If the force completely blocks the lumen of blood vessels, anoxia causes the cells to migrate or die, leaving at the site only the hyaline extracellular matrix and the movement does not occur efficiently and significant root resorption, due to the death of cementoblasts, can still happen. ${ }^{1}$

In the orthodontic movement, the greater or more concentrated is the force, the more likely it will not be efficient, because it will promote an absence of cells by their escape into the surrounding areas and/or their death. If this happens, the segment of the periodontal ligament will be amorphous and eosinophilic, occupied only by hyalinized extracellular matrix. With intense or concentrated forces tooth movement does not occur. If it occurs, it can only minimally be moved, but taking longer and at the expense of many symptoms and root resorption. ${ }^{1}$

For an orthodontic movement to be effective, it requires a biologically viable association, with preserved cells and tissue components. The orthodontic movement represents an event of biological and not physical nature; forces are the initial inducing agents of biological processes. When applying great or concentrated forces cellular life on the region is prevented and orthodontic movement to occur requires cells and vessels functioning normally.

When you apply an orthodontic force in teeth inserted or neighboring areas of thicker bone, the deflection is insignificant or absent. ${ }^{1}$ The force applied on the tooth tends to focus on its full potential on the periodontal ligament, which contains the cementoblasts, which protect the integrity of root. Hyalinization areas may be established by leakage and cell death, despite conventional orthodontic forces applied. Without the deflection due to the higher bone density, normal and conventional forces become dangerous to the tissue ligament during tooth movement along areas of idiopathic osteosclerosis. Any force applied to teeth in dense areas, directly affect the periodontal ligament.

In cases needing to move a teeth through denser areas such as idiopathic osteosclerosis bone type, the ideal would be to use smaller forces than those conventionally employed, compensating part of the force that would be dissipated by the adjacent bone deflection. By analogy, reducing the force corresponds to a discount, or compensation, because the bone deflection does not happen due to the higher density on site. In doing so, surprisingly a normal and even faster movement will occur, even in a denser area.

The same reasoning on force application in the orthodontic movement having part of their intensity dissipated by bone structures around the teeth can be extrapolated to the cortical bone (Fig 4). 
By moving teeth along cortical bone, if there is no special care to reduce force intensity, tooth displacement may occur, but the risk of further destruction of cementoblasts increases considerably, with the possibility of having more severe root resorption. ${ }^{1}$ In short, when moving teeth along cortical bone care should be taken to reduce the intensity of the forces, because the bone deflection will be much smaller, increasing the effects on the periodontal ligament and its structures.

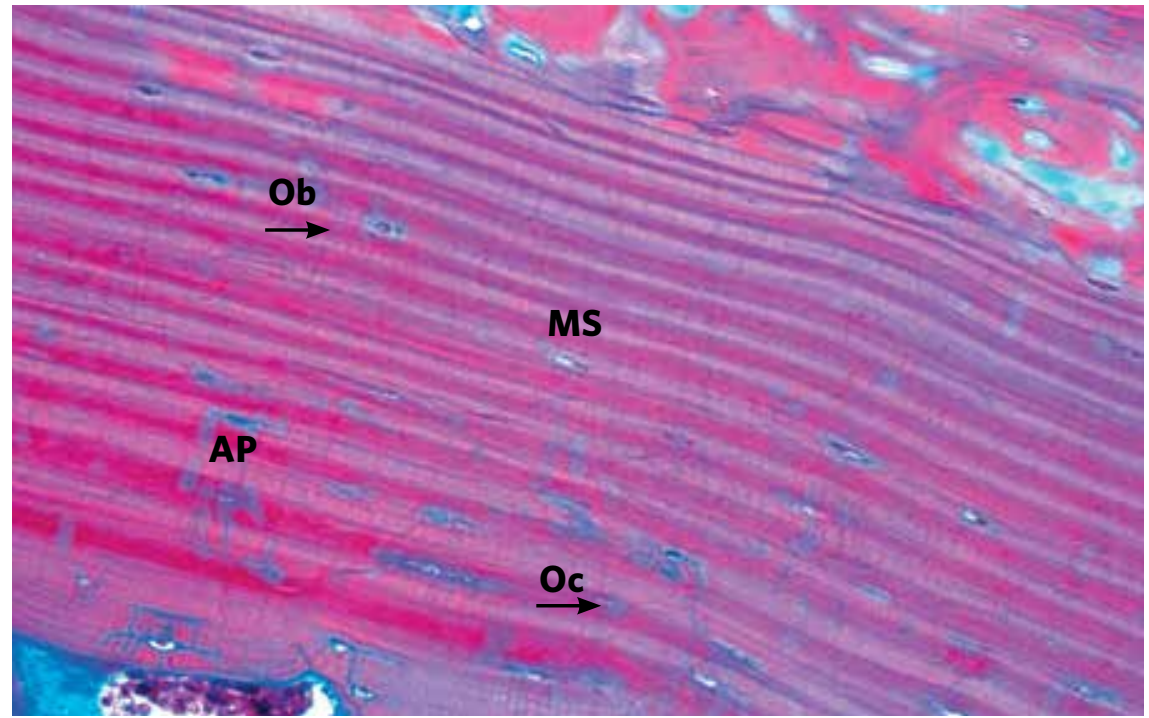

Figure 4 - Bone cortex constituted by various well defined layers of lamelar aposition (AP), which, in between, osteocytes can be noted. $\mathrm{Ob}=$ osteoblasts; $\mathrm{Oc}=$ osteoclasts. $(\mathrm{HE}, 25 \mathrm{x})$.
Some questions could be answered in future works:

1) What is the prevalence of root resorption in teeth that were moved into areas of denser bone, as Idiopathic Osteosclerosis, with and without the care mentioned earlier?

2) What is the prevalence of root resorption in teeth that were orthodontically moved along denser cortical bone, or even teeth that were anchored in the cortex?

3) Would differences in the frequency of root resorption in some types of teeth be related to bone density and the thickness of the cortical bone, features which vary in the different segments of the jaws?

\section{FINAL THOUGHTS}

Idiopathic osteosclerosis has no detectable cause-effect relationship, but may have been an earlier a Chronic Focal Sclerosing Osteitis, whose cause has been eliminated, such as a chronic periapical lesion, periodontal disease, pericoronaritis and occlusal trauma. A considerable number of induced sclerotic areas takes years or no longer return to normal, remaining indefinitely as part of the trabecular region, being diagnosed as idiopathic osteosclerosis.

While moving the teeth in these areas force intensity should be reduced because they do not exhibit any bone deflection and the same intensity will be applied on the periodontal ligament. The use of conventional forces in these cases can induce hyalinization areas and death of cementoblasts followed by root resorption, besides preventing an efficient tooth movement, which will become slower and symptomatic.

The same extrapolation can be done for tooth movement along cortical bone: They have insignificant or even no deflection, thus it may increase the risk of root resorption, including when teeth anchorage is performed in these structures. Further studies may detect more accurately the prevalence of root resorption, symptoms and efficiency of orthodontic movement when in dense areas of trabecular and/or cortical bone.

\section{REFERENCES}

1. Consolaro A. Reabsorções dentárias nas especialidades clínicas. 3a ed. Maringá (PR): Dental Press International; 2012

2. Wood NK, Goaz PW. Diagnóstico diferencial das lesões bucais. 2a ed. Rio de Janeiro: Guanabara Koogan; 1983. 